\title{
Analysis on the Situation of Equestrian Industry in China
}

\author{
Yao-Nan Li \\ PE college of Wuhan Business \\ University, Wuhan, Hubei, China \\ Email:.243011087@qq.com
}

\author{
Pei Cheng \\ PE college of Wuhan Business \\ University, Wuhan, Hubei, China \\ Email: 569780957@qq.com
}

\author{
Meng-Meng Yang \\ Tianjin University of Sport, Tianjin, \\ China \\ Email:263865573@qq.com
}

\begin{abstract}
Equestrian industry is an important part of sports industry development, and at present equestrian industry is in the stage of development in China. This article uses the method of searching for information and references, to detailed analysis of the current situation of the development of equestrian industry in China. Through the comparison of the methods to understand the current equestrian development advantages and disadvantages, to explore the development trend and path of equestrian industry in China.
\end{abstract}

Keywords-equestrian industry; horseracing lottery; the development path

\section{INTRODUCTION}

As the development blueprint of building a harmonious society, The rapid development of Chinese economy provides favorable development environment for the sports industry. Equestrian industry as an emerging industry and the new way of leisure, in the current situation, have a critical impact on China's economy, but is still faced with opportunities and challenges,.

\section{II.THE CURRENT SITUATION OF EQUESTRIAN INDUSTRY DEVELOPMENT}

Riding is one of the sports. According to the current situation of the development of international equestrian sector, equestrian industry mainly includes the horse activities and products. We will explore the current development situation of the equestrian club and horseracing lottery in China frist .

\section{A. Development Situation of Horseracing Industry}

Horseracing is a kind of sport which competitive the speed between the horses. horseracing has a long history in China. Qin Shihuang conquered the nations with the horses. For the unity of the nation, more than two thousand years after the prosperity and power, the great empire laid a solid foundation with the power of horses [1]. Due to historical reasons, the horseracing in China, with the development of reform and opening-up and market economy, the modernization brings the change of people's ideas, so people begin to yearning and pursuit the colorful horse culture .

In this background, the horseracing came into being, and developing rapidly. There was a typical jockey club which was the frist established in Shenzhen, China in 1991. Over the next 20 years, China's horseracing heated up, more than 400 across the country opened. Especially in recent years the international equestrian events gradually be born in China, for example, the Global Longines Equestrian Championship in Shanghai in 2016, and other world heavyweight championship tournament also held in China. The opportunities of China's horses to compete overseas are also more and more. With the speeding up of Chinese owners in overseas development, the communication of the horse racing competitions between home and abroad is gradually clear and more. And the senior owners are through their own experience and the development of racing to Contribute their power for China's horseracing. The owners effort for China's horseracing, has won the international horse racing organization's appreciation and acceptance, and aiso gain good reputation in the world.

\section{B. Development Situation of Equestrian Club}

Riding clubs in China emerged in the early 1990s, according to statistics, by 2009 , there are more than 300 riding clubs across the country, mainly distributed in the eastern developed cities. Most of the clubs concentrated in the big cities such as Beijing, Shanghai, Guangzhou, Shenzhen and other cities. The equestrian clubs have increased more than 60 in 2007, and a large number of high-end real estate projects and tourism development projects begin to enter the modern equestrian investment [2] .At present only Shanghai equestrian sports center and other several equestrian clubs are under the background of the state-run operations. Most equestrian clubs are private property operations, invested by some entrepreneurs. Due to technology, capital and management problems, most of the club's operation and management level is relatively backward, income level is generally low. Most of the investment is based on the personal interests of investors, and the project operation which investment lacks of rigorous scientific planning and specification of guidance [1]. Own to the current industry foundation is weak, the entire China's horse industry development lag behind, actually more than $95 \%$ of the first-class equestrian club are losing money.

\section{Development Situation of Horseracing Lottery}

Racing lottery is refers to the quizzes racing performance of a special kind of lottery tickets, around 1870 by Paris industrialists ole (PierreOller) invented a method of gambling, later became the world's most popular kind of 
horse gambling, generally hosted by the racetrack.

Hong Kong racing lottery first issued in 1931, the lottery developed as one of the most popular forms of gambling gradually. In 1960, horse gambling activities approved by the royal, from now on to the appearance of "emperor royal assent". In 1973, the authorities to eliminate the illegal action of the peripheral bet on horses, and approval of the Hong Kong Jockey Club set up legal betting station, then the station around all over Hong Kong soon. In mainland China, Guangzhou racetrack was established in January 1993, which is the first company in the mainland have gambling nature. Respectively there are three races which held every Tuesday, Thursday and Sunday, at that time the races attracted numerous local racing fans attention. However, yet racing lottery in policy is not allowed, according to the Financial Times reported that horseracing in China had been banned three times. Respectively, for the first time in 1992 published "the notice about resolutely put a stop to the activities of gambling nature", it is under in the pearl river delta region to Hong Kong horse racing "peripheral bet on horses" activity was rampant, and this bet on horse behavior produced the enormous destructive to the local public security order at the time, and the reputation of the Hong Kong jockey club also brought serious damage cases because of this activity; The second time in 2000, the central authorities allowed gambling cases, Guangzhou Jockey Club because of many factors such as corruption, the financial turmoil was halted, commission and ministry of supervision to stop racing notification to supervise the implementation, a large number of illegal racecourse was closed; The third time in 2001, Chengdu held "the first western China national equestrian festival" activities and by betting scandal, then national five ministries and commissions jointly combated betting phenomenon in the 2002 , so most racetracks of the mainland was closed.

In recent years, after the Wuhan city, Hubei province and domestic CPPCC joint submitted proposals to the central committee, then the national related department official have listed racing lottery on agenda. Wuhan became the only city to research and develop the horseracing lottery and undertake preparations of sports and racing games. Under this situation, horse racing lottery is expected to injected fresh blood to urban economy. To regional economic development, national tax, three agriculture problem, and the improvement of the animal husbandry, aquaculture, tourism and other related industrial chain, and low academic population employment, etc, it will have a promoting effect.

\section{ADVANTAGES AND DISADVANTAGES OF HORSERACING INDUSTRY DEVELOPMENT}

\section{A. The Advantage of Horseracing Industry Development \\ 1) Market Demand}

In China under the condition of sustainable and healthy social and economic development, and per capita GDP growth, high-end leisure sports are becoming more and more popular. Equestrian is regarded as high-end leisure sports, the tens of thousands of urban consumption crowd fall in love withe the amateur amusement ridding, so it has a wide prospect of market. The development momentum of China's overall economic is getting better and better, the state of the economy make equestrian industry gradually attracting more attention, for the equestrian industry's development and progress has laid a solid economic foundation.

\section{B. National Policy}

The economic base determines the superstructure, and the superstructure reaction in economic foundation, the stable social order and a good political environment created the conditions for the equestrian industry development. In October 2014, it is promulgated by the state council "about speed up the development of sports industry, promote the sports consumption of the several opinions". Countries from the perspective of industry for the first time identified the sports industry development plan, the national fitness become a national strategy for the first time, and the equestrian sports began to gain support again. During the two sessions in 2005 and 2015, the National People's Congress Liu Ying-zi submitted twice "on the advancing horse to horse racing industry pilot lottery issued advice". The emergence of the related policy and news are raised people's attention to the equestrian industry. At the same time in order to fundamentally solve industry standardization, specialization of the internal system problems , last year the Chinese Equestrian Association built "Chinese Equestrian Club Professional Examination and Rating 2010 Edition" system. Own to the policy, the equestrian club had a good development in our country [3].

\section{Cultural Deposits}

China is one of the oldest countries with breeding the horses in the world, also is one of the developed countries with the horse culture. If breeds is the "center" of the development of the equestrian sport in China, then our country's national equestrian original ecological culture symbol is the optimization "radius" [4]. Profound lasting horse culture laid the foundation for the development of equestrian industry. With the development and progress of the society, the increasingly advanced science and technology, the popularity of network media propaganda for the equestrian industry create the new conditions. For example WeChat horseracing subscribtions launch of the Chinese equestrian club WeChat influence ranking, etc. The equestrian club awareness create a good cultural environment for the development of equestrian industry in China.

\section{The Disadvantage of Equestrian Industry Development}

\section{1) Consumers Limited}

From the economic angle for the economic development of our country to be in good condition, but as a large country with a population of more than 1.3 billion, the regional economic development of our country and national income is unbalanced. Equestrian consumption for China's per capita income is high consumption, only the high 
earners of some economically developed cities have the spending power. so in a certain period of time, the equestrian industry cannot be development across the country. Although the equestrian sport as a noble temperament and unique charm of the sport attracts fashionable white-collar crowd more and more, but it is a large capital investment and consumption [5], so consumers of equestrian industry is insufficient effective demand.

\section{E. Absence of Relevant Policies and Regulations}

Though in about several opinions of the development of sports industry, the state council made it clear that equestrian sport is popular with the audience and have development space. But because of an explicit laws and regulations to improve and constraint the development of equestrian sport in our country, so it can't timely solve the problems, and this state is bad for the development of the industry. On the other hand, leaders of the country's personal interests have a certain influence on the development of sports industry, such as state President Xi Jinping likes football very much, for the rise of soccer schools across the country has a positive role in the development of football sports, currently equestrian sport lack the drive effect.

\section{F. Cultural Difference}

Due to the lack of integration of horseracing traditional cultural, at the same time, shadow is rigid named as noble sports become obstacles in the development of equestrian sport[3].In the rapid economic development of modern society, the horse culture is not widespread mass base. Dealing with China's different regions of the horse culture conflict is the important cultural question that has to face. Even in recent years, the famous rider HuaTian in the equestrian sport can budding in Rio DE janeiro Olympic Games, it still does not as popular as like tennis star LiNa and basketball star YaoMing, so the lack of star power to drive the equestrian sports.

\section{G. Technical Level}

In our country, the equestrian industry is still in its infancy, equestrian club technical environment in our country is still relatively backward. At present, the majority of equestrian clubs are built by some equestrian amateurs, and these clubs have no professional management, without the support of funds and no trading platform, so it is not conducive to the development of Chinese equestrian club. Wuhan Heping equestrian club general manager thinks, China horse industry in the 21 st century is lack of equestrian professionals. This reflects the human resources issues facing equestrian industry of our country. For this reason many equestrian club are willing to take high salary to employ foreign coach. In our country, although there are a lot of equestrian trainers can ride very well but the professional knowledge and business philosophy knows little [6], all of these factors limiting the development and progress of equestrian industry.

\section{CONCLUSION}

\section{A. Development Trend of Equestrian Industry}

Just like all the new things, the equestrian industry will be confronted with obstacles in the beginning, so the start is difficult. Maybe in the unnormal aspect of software are weak, for example the horse and the rider's training, thoroughbred horse identification, Retired horse processing .etc. But the hardware facilities of questrian sport in China actually have reached a higher level, such as Guangdong, Jiangsu and Shandong province have owned world-class racetrack, so it is capable to undertake international equestrian events.

Because of the fun, healthy and noble characteristics of riding, the private owner number increased continuously in recent years, so the demand for high-grade horses and related products began to rise. A growing number of wealthy Chinese people start to enter the industry, especially in economically developed areas, so the Chinese equestrian industry has big space and good prospects for development.

There are more than 150 countries and regions around the world have horses, and the legalization of horseracing have 67 countries and regions. The developed countries of Horseracing includ the United States, Australia, Britain, France and Hong Kong, etc., in the above countries and regions, the horse racing industry have greater contribution to its economic growth.But due to the increasing labor costs in developed countries, the racing economy is on the basis of stable decreasing trend. China is a vast country, own large population and the labour surplus is a prominent phenomenon, which is the best period of the development of horse racing industryat present [7].

\section{B. Development Path of Equestrian Industry}

In the long run, the development prospect of equestrian industry in China is a bright future, we need to do to better meet market demand, make scientific management and planning, use scale to attract consumers.As the trend of stable economic development, countries should step up to the equestrian industry funds and policy support, and raise public awareness of horse racing, adjust and improve the equestrian industry structure and promote the development of relevant industries, forming new economic growth point, to promote investment in the equestrian industry, and cultivate more professionals, we should do the basic work better for the horse racing industry fristly.

\section{REFERENCE}

[1] Sun Zhuo Zhang Teng. "our country equestrian club management present situation and the countermeasure analysis, 2013.

[2] fang-min li. Study and design of equestrian club [D], 2010.

[3] li xiang, Xia Yunjian. Equestrian club present situation analysis and strategy research in China [J], 2013.

[4] Sun Dechao Xu Jun. Chinese equestrian sport development problems and path selection, 2013

[5] GuanHui. Difficulties and prospects of the development of Chinese equestrian studies, 2013.

[6] lodge attempted li xiao-feng chang, Liu Yuanfu, Chen wenkai, li zheng. The SWOT analysis of the industrialization of equestrian sport in 
China, 2013.

[7] Michael Ford. From 1995 to 2003, the trend of world blood horse breeding [A], 2005 